\title{
Guideline for the assessment of trauma centres for South Africa
}

Timothy Craig Hardcastle, Elmin Steyn, Kenneth Boffard, Jacques Goosen, Mande Toubkin, Andre Loubser, Denis Allard, Steve Moeng, David Muckart, Petra Brysiewicz, Lee Wallis, on behalf of the Executive Committee of the Trauma Society of South Africa

Introduction. Trauma is a well-known leading cause of unnatural death and disability in South Africa. Internationally the trend is moving toward systematised care.

Aim. To revise the Trauma Centre Criteria of the Trauma Society of South Africa and align these with the terminology and modern scope of emergency care practice, using best-care principles as a prelude to the development of trauma systems in South Africa.

Methodology. Revision of existing documents of the Trauma Society of South Africa, the Emergency Medicine Society of South Africa and the Critical Care Society of Southern Africa, where these are relevant to the care of trauma. The committee attempted to harmonise these criteria with the goals of the World Health Organization essential trauma care guidelines for trauma centres and trauma systems. Wide expert consultation was undertaken to refine the criteria before final compilation.
Results and recommendations. Four levels of trauma care facility are outlined, with the criteria focusing on the trauma-specific requirements of the facilities and their place in the greater trauma system. Accreditation of hospitals according to the criteria will allow for appropriate transfer and designation of patient destination for trauma patients and will improve the quality of care provided. The criteria address structural, process and human resource requirements and medical aspects for the accreditation of various level of trauma centre.

Conclusion. There is a great opportunity to apply best practice criteria to improve the care of trauma in South Africa and improve patient outcome.

S Afr Med J 2011;101:189-194.
Inkosi Albert Luthuli Central Hospital/University of KwaZulu-Natal, Durban Timothy Craig Hardcastle, MB ChB, MMed (Chir), FCS (SA),Vice President, Trauma Society of South Africa

David Muckart, MB ChB, MMedSci, ACS (SA), Cert Crit Care (SA),

Representative of the Critical Care Society of Southern Africa

Trauma Surgery, Chris Barnard and Vincent Pallotti hospitals, Cape Town Elmin Steyn, MB ChB, MMed (Surg), FCS (SA), President, Trauma Society of South Africa

Charlotte Maxeke Johannesburg Hospital and University of the Witwatersrand, Johannesburg

Kenneth Boffard, BSc (Hons), MB, FRCS, FRCS (Edin), FRCPS (Glasg), FACS, Immediate Past President, Trauma Society of South Africa

Charlotte Maxeke Johannesburg Hospital and University of the Witwatersrand, Johannesburg

Jacques Goosen, MB ChB, FCS (SA), Cert Trauma (SA), Honorary Treasurer Trauma Society of South Africa

Steve Moeng, MB ChB, Dip PEC (SA), HDip (Surg) (SA), FCS (SA)

Netcare National Trauma and Transplant Co-ordinator

Mande Toubkin, CCRN (ICU \& Trauma), Secretary, Trauma Society of South Africa

Pelonomi Hospital and University of the Free State, Bloemfontein Andre Loubser, MB ChB, MMed (Surg)

G F Jooste Hospital, Cape Town

Denis Allard, General Surgery (Brussels), FCS (SA)

School of Nursing, University of KwaZulu-Natal

Petra Brysiewicz, CCRN (ICU \& Trauma), MCur, PhD, President of the Emergency Nurses Society of South Africa

Emergency Medicine, Universities of Cape Town and Stellenbosch Lee Wallis, MB ChB, MD, DIMC, Dip Sport Med, FRCS (A\&E), FCEM, FCEM (SA), Emergency Medicine Society of South Africa

\section{Introduction}

Trauma is a disease process that is intimately related to man's interaction with other people and the environment. Trauma is the leading cause of non-natural death and a major cause of permanent disability and the economically active population group is most affected, thus increasing the real costs of injury to society. ${ }^{1}$

Great advances have been made in the treatment of trauma with the establishment, firstly in Birmingham in the $\mathrm{UK}^{2,3}$ and later in the USA, of so-called 'trauma centres' - comprehensive centres of excellence where each specialty and sub-specialty of medical provider and allied health professional is present to provide initial assessment, quality resuscitation and definitive care and to speed the recovery of the patient with appropriate rehabilitation facilities. This has positively impacted on overall outcome. ${ }^{4,5}$

South Africa followed this trend by establishing major trauma services at Johannesburg, ${ }^{3}$ Groote Schuur, Tygerberg, Pelonomi and Inkosi Albert Luthuli Central hospitals. In the private sector Milpark and several other hospitals have established trauma facilities led by trauma surgeons.

Trauma is a large component of the emergency surgical and orthopaedic workload at most public hospitals. ${ }^{6}$ Trauma surgery is now a separate sub-specialist discipline in surgery, ${ }^{7}$ and emergency medicine is a specialty in its own right. ${ }^{8}$ This will improve overall care of trauma victims and others presenting with medical emergencies.

Initially the trauma system consisted only of 'centres of excellence' in a sea of indifference. However, it was soon apparent that including the entire spectrum of caregivers resulted in better outcomes and led to the surgeon-led trauma systems typical of many developed countries. ${ }^{9}$ Trauma systems, where the services and facilities outside the major trauma centres were included to provide optimal care and referral of the appropriate patient to the appropriate higher level of care facility, have improved outcomes. These systems include integrating the pre-hospital fire and medical rescue services (emergency medical services) into the matrix and developing sufficient inter-facility and inter-service communications systems to ensure that the right patient gets to the right level of care within a defined optimal period of time, ${ }^{4,5}$ including rehabilitation and allied health providers. ${ }^{10}$ 
The Trauma Society of South Africa (TSSA) is at the forefront of the setting of standards for the accreditation of private and public trauma care facilities.

\section{Methodology}

David Muckart, then President of the TSSA, reviewed the American College of Surgeons Trauma Centre Criteria and placed them in the South African context. ${ }^{10}$ This document served as the basis for trauma centre development in South Africa. It was updated in 2004, and in 2007 the Colleges of Medicine of South Africa accepted it as the framework for sub-speciality training in trauma surgery. The document has also been accepted by the Health Professions Council of South Africa (HPCSA) for accreditation of institutions for training of surgeons and surgical sub-specialists. ${ }^{11}$ The present document has been updated and ratified by the Executive Committee of the TSSA, including input from the Critical Care Society of Southern Africa, Emergency Medicine Society of South Africa and Association of Surgeons of South Africa. The requirements are in line with or exceed those of the World Health Organization and other national documents. ${ }^{12-19}$

These criteria will be refined regularly when suitably trained practitioners in emergency medicine and trauma surgery qualify and fill the positions in hospitals and emergency centres.

\section{Disease profile}

The management of trauma requires surgical capacity, whereas many emergencies can be managed at most hospital levels, provided suitably trained emergency medicine practitioners are available. A hospital's ability to manage trauma must therefore be independently assessed, so that it can be appropriately designated and correctly placed in the greater trauma system, while stressing that the trauma patient is managed by the entire emergency and surgical team.

\section{Definitive care facilities}

Essential to the development of a trauma care system is the designation of definitive trauma care facilities. The trauma care system is the network of facilities that provides a full spectrum of care for all injured patients. Trauma centres should not be confused with emergency centres, where initial emergency care is provided to all emergencies, including trauma. Hospitals may have one designation level of emergency centre and another level of trauma centre designation.

When adequate level I trauma centre resources are available, additional level II centres may not be necessary. Similarly, when level I and level II trauma centres can provide care for the volume of trauma patients in the region, level III trauma centres may not be necessary; however, accredited emergency centres are needed, as they treat a variety of emergencies. In less densely populated areas and rural areas, level II and level III trauma centres are essential. In trauma systems, the designating authority is responsible for determining the anticipated volume of major trauma patients and assessing available resources to determine the optimal number and level of trauma centres in the area. This is one of the challenges facing South Africa's health care system.

Additionally, effective trauma systems must have a lead hospital, which must be the highest level available within the trauma system. It should be designated as such with delegated authority to oversee the entire system through outreach and in-reach. In many areas, level I centres will serve as the lead hospitals. In systems in less dense populations, level II facilities may assume this role. In smaller community and rural settings, level III centres must serve as the lead hospitals. The guidelines have been expanded to include level IV facilities, as many communities have only clinics and primary health care facilities that must provide basic trauma care.

\section{Goals of the guidelines}

These standards are intended to provide initial classification of hospital care and the staffing, resources and equipment essential to provide quality care (Table I).

The system is divided into four levels of care, and a particular centre may be awarded a different level of trauma verification from their designation in terms of their emergency centre or hospital status. For example one could have a level II trauma centre within a level I emergency centre if the hospital meets all the criteria for a major emergency centre but does not meet all the criteria to be a level I trauma centre. Alternatively, a hospital that focuses on a particular organ system (e.g. a urology or heart hospital) might only be able to meet level IV trauma centre criteria.

\section{Trauma centre descriptions:}

\section{(Fig. 1, Table I)}

\subsection{Level I (major trauma referral centre)}

The level I facility is a regional resource trauma centre, usually a tertiary care facility central to the trauma care system. Ultimately, all patients who require the resources of the level I centre should have access to it. It must be capable of providing leadership and total care for every aspect of injury, from prevention through rehabilitation, and have 24 -hour availability of all major specialties. In its central role, the level I centre must have adequate depth of resources.

Level I: Major trauma centre

Level II: Urban trauma centre

Level III: Community hospital

Level IV: Primary health care centre

Fig. 1. Trauma centre levels.

Because of the large personnel and facility resources required for patient care, education and research, most level I trauma centres are university-based teaching hospitals. However, other hospitals willing to commit these resources may meet the criteria for level I recognition.

Level I trauma centres are also responsible for providing leadership in education, research and system planning that extends to all hospitals caring for injured patients in their region. Medical education programmes should include undergraduate and postgraduate training in trauma for doctors and nurses, and involvement with the training of pre-hospital providers. Education may include continuing medical education, personnel exchanges, outreach and other approaches appropriate to the local situation. Research and prevention programmes are essential for a level I trauma centre.

\subsection{Level II (urban trauma centre)}

The level II trauma centre is a hospital that is also expected to provide initial definitive trauma care regardless of the severity of injury, with 24-hour medical cover, including the common specialties.

However, depending on location, patient volume, personnel and resources, the level II trauma centre may be unable to provide the same comprehensive care as a level I trauma centre. Patients with complex injuries, e.g. requiring advanced and extended surgical critical care, may therefore have to be transferred to a level I centre. Level II trauma centres may be the most prevalent facility in a community and manage most trauma patients.

The level II trauma centre can be an academic institution or a public or private community facility located in an urban, suburban or rural area. Educational outreach, research and prevention programmes are similar to those required by a level I trauma centre, but, research is not 


\begin{tabular}{lllll}
\multicolumn{5}{c}{ Level } \\
\hline I & II & & III & IV
\end{tabular}

\section{A. Hospital organisation}

1. Trauma service (trauma care from patient entry)

2. Designated head of trauma (registered trauma surgeon)

3. Trauma multidisciplinary team

4a. Designated head of EM (registered EM specialist)

4b. Designated head of EM (registered medical practitioner)

5. Hospital departments
a. EM
b. General surgery
c. Anaesthesia
d. Orthopaedic surgery
e. Neurosurgery

$\begin{array}{llll}\mathrm{E} & \mathrm{D} & \mathrm{D} & \\ \mathrm{E} & \mathrm{D} & \mathrm{D} & \\ \mathrm{E} & \mathrm{D} & \mathrm{D} & \\ & \mathrm{E} & \mathrm{D} & \\ & \mathrm{E} & \mathrm{D} & \\ & & & \\ \mathrm{E} & \mathrm{E} & \mathrm{D} & \mathrm{D} \\ \mathrm{E} & \mathrm{E} & \mathrm{D} & \mathrm{D} \\ \mathrm{E} & \mathrm{E} & \mathrm{D} & \mathrm{D} \\ \mathrm{E} & \mathrm{E} & \mathrm{D} & \\ \mathrm{E} & \mathrm{D} & \mathrm{D} & \end{array}$

\section{B. Clinical capabilities}

Clinical discipline availability

1. In-house 24 hours a day (available within 10 minutes)

a. EM

b. Trauma surgery/trauma critical care

2. On call and available within 20 minutes
a. General surgery
b. Anaesthesiology

3. On call and available within 60 minutes

a. Anaesthesiology

b. Cardiac surgery

c. Cardiology

d. General surgery

e. Emergency medicine

f. Family medicine

f. Hand surgery

g. Infectious diseases

h. Intensive care

i. Internal medicine

j. Microvascular surgery

k. Neurosurgery

1. Nuclear medicine

m. Obstetrics/gynaecology

n. Ophthalmic surgery

o. Oral/maxillofacial surgery

p. Orthopaedic surgery

q. Paediatric surgery

r. Paediatrics

s. Plastic surgery

t. Pulmonary medicine

u. Radiology

v. Thoracic surgery

w. Urology

x. Vascular surgery

\section{Facilities/resources}

1. Emergency centre

a. Personnel

1. Designated doctor in charge of the shift

2. Doctor with special competence in care of critically injured is a designated member of the trauma team and is physically present in the emergency department 24 hours a day

3. ATLS $^{\circledast}$-trained personnel 24 hours a day

4. ACLS $^{\mathrm{mm}}$-trained personnel 24 hours a day

5. APLS ${ }^{\circledast}$ PALSTM-trained personnel 24 hours a day

\begin{tabular}{|c|c|c|c|}
\hline $\mathrm{E}$ & $\mathrm{E}$ & $\mathrm{E}$ & $\mathrm{D}$ \\
\hline $\mathrm{E}$ & $\mathrm{D}$ & $\mathrm{D}$ & \\
\hline $\mathrm{E}$ & $\mathrm{E}$ & $\mathrm{D}$ & \\
\hline $\mathrm{E}$ & $\mathrm{E}$ & $\mathrm{D}$ & \\
\hline $\mathrm{n} / \mathrm{a}$ & $\mathrm{n} / \mathrm{a}$ & $\mathrm{E}$ & \\
\hline E & $\mathrm{D}$ & & \\
\hline $\mathrm{E}$ & $\mathrm{D}$ & & \\
\hline $\mathrm{n} / \mathrm{a}$ & $\mathrm{n} / \mathrm{a}$ & $\mathrm{E}$ & $\mathrm{D}$ \\
\hline \multirow[t]{2}{*}{$\mathrm{n} / \mathrm{a}$} & $\mathrm{n} / \mathrm{a}$ & E & \\
\hline & & & $\mathrm{D}$ \\
\hline \multirow[t]{2}{*}{$\mathrm{E}$} & $\mathrm{D}$ & & \\
\hline & $\mathrm{E}$ & $\mathrm{D}$ & \\
\hline $\mathrm{E}$ & $\mathrm{D}$ & & \\
\hline $\mathrm{E}$ & $\mathrm{E}$ & $\mathrm{D}$ & \\
\hline $\mathrm{E}$ & $\mathrm{D}$ & & \\
\hline $\mathrm{E}$ & $\mathrm{D}$ & $\mathrm{D}$ & \\
\hline $\mathrm{E}$ & $\mathrm{E}$ & $\mathrm{D}$ & \\
\hline $\mathrm{E}$ & $\mathrm{D}$ & $\mathrm{D}$ & \\
\hline $\mathrm{E}$ & $\mathrm{D}$ & & \\
\hline \multirow[t]{2}{*}{ E } & $\mathrm{E}$ & $\mathrm{D}$ & \\
\hline & $\mathrm{E}$ & $\mathrm{D}$ & \\
\hline E & $\mathrm{E}$ & $\mathrm{D}$ & \\
\hline $\mathrm{E}$ & $\mathrm{E}$ & $\mathrm{D}$ & \\
\hline E & $\mathrm{D}$ & & \\
\hline E & $\mathrm{E}$ & $\mathrm{D}$ & $\mathrm{D}$ \\
\hline E & $\mathrm{D}$ & & \\
\hline E & $\mathrm{D}$ & $\mathrm{D}$ & \\
\hline E & $\mathrm{D}$ & & \\
\hline I & II & III & IV \\
\hline E & $\mathrm{E}$ & E & D \\
\hline E & E & $\mathrm{D}$ & \\
\hline E & $\mathrm{E}$ & $\mathrm{D}$ & $\mathrm{D}$ \\
\hline \multirow[t]{2}{*}{$\mathrm{E}$} & E & $\mathrm{D}$ & $\mathrm{D}$ \\
\hline & $\mathrm{E}$ & $\mathrm{D}$ & \\
\hline
\end{tabular}


6. Nursing personnel with specific training in trauma care who provide continual monitoring of the trauma patient from hospital arrival to disposition in ICU, OR or patient care unit

b. Equipment for resuscitation

Required for patients of all ages. Shall include but not be limited

to:

1. Airway control and ventilation equipment, including

laryngoscopes, endotracheal tubes of all sizes, bag-mask

resuscitator, pocket masks, rescue devices and oxygen

2. Pulse oximetry

3. End-tidal CO2 determination/tube placement detector device

4. Suction devices (portable or wall mounted)

5. Electrocardiograph monitor defibrillator/pacer

6. Standard intravenous fluids and administration devices, including large-bore IV catheters

7. Apparatus to establish central venous catheter and venous pressure monitoring

8. Sterile surgical sets for:

a. Cricothyroidotomy

b. Thoracotomy and tube thoracostomy

c. Vascular access (cutdown)

d. Chest decompression

9. Drugs necessary for emergency care as per EDL

10. X-ray availability, 24 hours a day

11. Two-way communication with emergency transport system

12. Skeletal traction devices

13. Arterial catheters and monitoring devices

14. Thermal control equipment

a. For patient - patient warming

b. For blood and fluids - high capacity

c. For blood and fluids - fluid warming

2. Operating theatre

a. Personnel

Operating room adequately staffed in-house and immediately available 24 hours a day

b. Equipment

Required for patients of all ages. Shall include but not be limited to:

1. Cardiopulmonary bypass capability

2. Operating microscope

3. Thermal control equipment

a. For patient - patient warming blanket

b. For blood and fluids - high capacity

c. For blood and fluids - fluid warming

4. X-ray capabilities including c-arm image intensifier available 24 hours a day

5. Endoscopes

6. Craniotomy instruments

7. Equipment appropriate for fixation of long bone and pelvic fractures

3. Post-anaesthetic recovery room

(ICU is acceptable)

a. Personnel

1. Registered nurses

b. Equipment

1. Equipment for the continuous monitoring of temperature,

haemodynamics and gas exchange

2. Equipment for the continuous monitoring of intracranial pressure

3. Pulse oximetry

4. End-tidal $\mathrm{CO}_{2}$ determination

5. Active patient warming device

4. Intensive care unit for trauma patients with trained staff

a. Personnel

1. Trauma specialist ultimately responsible for trauma care

2. Physician with training in critical care available to ICU 24 hours a day

3. Nursing: 24 hours nursing acuity per patient (ICU)

12 hours nursing acuity per patient (HC) 


\section{b. Equipment}

Appropriate monitoring and resuscitation equipment for all ages

shall include but not be limited to:

1. Airway control and ventilation equipment, including

laryngoscopes and endotracheal tubes of all sizes, bag-mask

resuscitator, pocket masks, rescue devices and oxygen

2. Mechanical ventilation equipment

3. Pulse oximetry

4. End-tidal $\mathrm{CO}_{2}$ determination

5. Suction devices

6. Monitor defibrillator

7. Invasive pressure monitoring

5. Additional clinical services

a. Physiotherapy

b. Psychotherapy

c. Occupational therapy

d. Dietetics

e. Acute haemodialysis capability

f. Acute burn care capability

g. Acute spinal cord/head injury management capability

h. Access to comprehensive rehabilitation service

6. Specialist radiology services
a. Computed tomography
b. Interventional radiology
c. Magnetic resonance imaging
d. Sonography

7. Clinical laboratory service

(available 24 hours a day)

a. Full blood count

b. Urea and electrolytes

c. Blood glucose

d. Urinalysis

e. Blood typing and cross-matching

f. Coagulation studies

g. Thrombo-elastography

h. Comprehensive blood bank or access to banked blood with adequate storage facilities

i. Blood gas, lactate and $\mathrm{pH}$ determinations

j. Microbiology

k. Drug and alcohol screening

D. Quality assurance/quality improvement

1. Documented evidence of ongoing quality improvement programme

2. Outcomes-based trauma registry

3. Morbidity and mortality review

4. Trauma CPD (multidisciplinary) - at least monthly

5. Pre-hospital care feedback (documented)

6. Published on-call schedule must be maintained for all specialties deemed essential

7. Times and reasons for trauma divert must be documented and reviewed

$\begin{array}{llll} & \text { E } & \text { E } & \text { E } \\ \text { E } & \text { E } & \text { D } & \\ \text { E } & \text { E } & \text { E } & \\ & \text { E } & \text { E } & \text { E } \\ & \text { E } & \text { E } & \text { E } \\ \text { E } & \text { E } & \text { E } & \\ & \text { E } & \text { E } & \text { D }\end{array}$

\section{E. Outreach programme}

Telephone and/or on-site consultations with physicians and nurses of the community and outlying areas

\section{F. Preventive/public education}

1. Epidemiology research

a. Collaborate with other organisations in injury prevention education

\section{G. Trauma research programme}

(own or in collaboration with an academic department)

1. All research must have ethics approval

2. Regular meeting of multidisciplinary research groups

3. Evidence of multidisciplinary research productivity

a. Presentation at local/regional/national meetings

b. Publications in peer-reviewed journals

\begin{tabular}{|c|c|c|}
\hline $\mathrm{E}$ & E & $\mathrm{E}$ \\
\hline $\mathrm{E}$ & E & E \\
\hline E & $\mathrm{E}$ & E \\
\hline $\mathrm{E}$ & E & E \\
\hline \multirow[t]{2}{*}{$\mathrm{E}$} & $\mathrm{E}$ & D \\
\hline & $\mathrm{E}$ & $\mathrm{E}$ \\
\hline \multirow[t]{3}{*}{$E$} & D & $\mathrm{D}$ \\
\hline & $\mathrm{E}$ & $\mathrm{E}$ \\
\hline & E & E \\
\hline $\mathrm{E}$ & E & $\mathrm{D}$ \\
\hline $\mathrm{E}$ & $\mathrm{E}$ & $\mathrm{D}$ \\
\hline $\mathrm{E}$ & E & E \\
\hline $\mathrm{E}$ & $\mathrm{E}$ & $\mathrm{D}$ \\
\hline E & E & E \\
\hline $\mathrm{E}$ & $\mathrm{E}$ & $\mathrm{D}$ \\
\hline E & E & $\mathrm{D}$ \\
\hline $\mathrm{E}$ & $\mathrm{E}$ & $\mathrm{E}$ \\
\hline $\mathrm{E}$ & $\mathrm{E}$ & $\mathrm{E}$ \\
\hline $\mathrm{E}$ & $\mathrm{D}$ & $\mathrm{D}$ \\
\hline $\mathrm{E}$ & $\mathrm{D}$ & $\mathrm{D}$ \\
\hline $\mathrm{E}$ & E & E \\
\hline $\mathrm{E}$ & D & \\
\hline $\mathrm{E}$ & $\mathrm{D}$ & \\
\hline $\mathrm{E}$ & D & \\
\hline
\end{tabular}




\section{H. Trauma service support personnel}

Trauma programme manager (co-ordinator) - direct reporting to

hospital manager/clinical executive/medical manager and trauma director

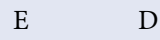

I. Organ procurement activity

Required referral of potential donors (documented evidence)

E E $\quad$ E

J. Helipad access

(all applications for verification received after 1 January 2011)

$\mathrm{E}$

$\mathrm{D}$

$\mathrm{D}$

K. Other

1. Annual declaration by the head of trauma that standards

have been maintained, in order to maintain verification status

2. Re-verification inspection required every 3 years

3. Access to clinical forensic support services

E E D

E E E

E E E

$\mathrm{E}=$ essential for verification at that level (all essential must be met for grading); $\mathrm{D}=$ desirable, but not essential for verification at that level; blank = not applicable to that level of care; $\mathrm{n} / \mathrm{a}=\mathrm{not}$ applicable; ICU = intensive care unit; $\mathrm{OR}=$ operating room; $\mathrm{EDL}=$ Essential Drugs List; $\mathrm{HC}=$ high care: $\mathrm{CPD}=$ continuing professional development.

an essential criterion. In areas where there is no level I centre, the level II centre should be responsible for education and system leadership.

\subsection{Level III (community hospital)}

The level III trauma centre serves communities without immediate access to a level I or II institution. Level III trauma centres can provide prompt assessment, resuscitation, basic emergency operations and stabilisation, and arrange for possible transfer to a facility that provides definitive trauma care. They must have prompt availability of general surgeons or general practitioners with surgical expertise, and planning for care of injured patients requires established early transfer systems and standardised treatment protocols. Level III trauma centres are generally not appropriate in an urban or suburban area with adequate level I and or level II resources.

Most rural hospitals, and perhaps some smaller urban hospitals, will be level III facilities.

\subsection{Level IV (primary health care facility)}

Level IV trauma facilities provide basic trauma life support before patients are transferred for definitive care. Most will exist in remote areas where no higher level care is available, may be a clinic rather than a hospital, and may or may not have a doctor available. However, because of geographical isolation, the level IV trauma facility is the primary care provider. If willing to make the commitment to provide optimal care, given its resources, the level IV trauma facility should be integral to the inclusive trauma care system.

A level IV trauma facility must have a good working relationship with the nearest level I, II or III trauma centre to develop a rural trauma system with realistic standards based on available resources. Optimal care in rural areas can be provided by skilful use of existing professional and institutional resources supplemented by treatment guidelines that result in enhanced education, resource allocation, and appropriate designation for all levels of providers. The level IV facility must have a committed health care provider who can provide leadership and sustain the affiliation with other centres.

\section{Implementation}

Requests by a hospital or state health system for assessment will result in the following. The Verification Committee of the Trauma Society will provide a questionnaire document followed by a visit to verify the centre at the standard requested. Verification will be for 3 years provided all criteria are complied with and annual reports prove that the standard is being maintained.

The College of Surgeons has accepted the criteria as binding on training institutions that intend to train in the sub-speciality of trauma surgery. The HPCSA has accepted the criteria for the recognition of training in trauma by surgical trainees and sub-specialty trainees. ${ }^{11}$

\section{Conclusion}

Trauma care is being refined in South Africa, which has a great legacy of trauma surgical leadership and innovation. The TSSA, the professional body of experts in this field, wishes to enable all public or private hospitals/institutions to know the required standards and encourages application for accreditation. Applications for accreditation of a service should be in writing to the President of the Trauma Society, at assa@worldonline.co.za.

\section{References}

Muckart DJJ. Trauma - the malignant epidemic. S Afr Med J 1991;79:93-95.

. Morris MS. Accident and emergency medicine - quo vadis? Trauma and Emergency Medicine 1993;9:905-906.

Boffard KD. In Memoriam. Trauma and Emergency Medicine 1993;9:851

4. Trunkey DD. The medical world is flat too. World J Surg 2008;32:1583-1604.

. Blackwell T, Kellam JF, Thomason M. Trauma care systems in the United States. Injury. International Journal of the Care of the Injured 2003;34:735-739.

6. Van der Jagt D, Golele R, Govender S, et al. Orthopaedic injuries in state hospitals. S Afr Med J 2008;98:601-602.

Ministry of Health. Government Gazette 17 August 2007

8. Ministry of Health. Government Gazette 13 December 2004

. Gwinnutt CL, Driscoll PA, Whittaker J. Trauma systems - state of the art. Resuscitation 2001;48:1723 .

Committee on Trauma, American College of Surgeons. Resources for the Optimal Care of the Injured Patient: 1999 Update. American College of Surgeons. Chicago: American College of Surgeons, 1999.

11. Sub-specialty Certificate in Trauma Surgery of the College of Surgeons of South Africa: Cert Trauma Sub-specialty Certificate in Trauma Surgery of the College of Surgeons of South Africa: Cert Trauma
Surgery (SA). http://www.collegemedsa.ac.za/view_exam.asp?Type=Link\&ExamID=117 (accessed 10 Surgery (SA)

12. Council on Hospital Accreditation for South Africa. Emergency Centre Standards. Cape Town, 2007.

12. Council on Hospital Accreditation for South Africa. Emergency Centre Standards. Cape Town, 2007. Surg 2006;30:919-929.

14. Mock C, Lormand JD, Goosen J, Joshipura M, Peden M. Guidelines for essential trauma care. Geneva: World Health Organization, 2004.

15. Sasser S,Varghese M, Kellermann A, Lormand JD. Prehospital trauma care systems. Geneva: World Health Organization, 2005.

16. Goosen J, Bowley D, Degiannis E, Plani F. Trauma care systems in South Africa. Injury. International Journal of the Care of the Injured 2003;34:704-708.

17. Goosen J, Veller M. Trauma and emergency surgery: A South African model. World J Surg 2008;32:16221625

18. Emergency Medicine in South Africa. Johannesburg: Emergency Medicine Society of South Africa November 2009 .

Guidelines for Intensive Care in South Africa. South African Journal of Anaesthesia and Analgesia 2006; Practical Guidelines, section 7: 7.1-7.8

Accepted 17 December 2010 